\title{
Links between ill health and regional economic performance: Evidence from Swedish longitudinal data
}

Word count: 6120

\begin{tabular}{|c|c|c|}
\hline $\begin{array}{l}\text { Bo Malmberg* } \\
\text { bo.malmberg@humangeo.su.se }\end{array}$ & $\begin{array}{l}\text { S V Subramanian } \\
\text { svsubram@hsph.harvard.edu }\end{array}$ & $\begin{array}{l}\text { Eva Andersson } \\
\text { eva.andersson@ibf.uu.se }\end{array}$ \\
\hline Stockholm University & Harvard School of Public & Uppsala University \\
\hline Department of Human Geograph & y Health & Institute for Housing and Urban \\
\hline SE-106 91 Stockholm & \multicolumn{2}{|c|}{ Department of Society, HumanResearch } \\
\hline Sweden & Development and Health & SE-801 29 Gävle \\
\hline www.humangeo.su.se & Boston MA 02115 & Sweden \\
\hline+468164853 & USA & www.ibf.uu.se \\
\hline & 6174326299 & +46264206516 \\
\hline
\end{tabular}

Acknowledgement: S. V. Subramanian is supported by the National Institutes of Health Career Development Award (NHLBI 1 K25 HL081275). 


\section{Links between ill health and regional economic performance: Evidence from}

\section{Swedish longitudinal data}

\section{ABSTRACT}

While poor health has been associated with economic outcomes at the national level, its effect on economic outcomes at the individual and local level remains less known. Using nationally representative longitudinal data from Sweden, we examined the extent to which an individual's poor health leads to poor economic outcomes for the individual. In order to understand the effects of poor health at a regional level, we also examined the spill-over effects of the individual's poor health on the economic outcomes of the people linked to the individual. We report an association between an individual's poor health and both that individual's subsequent adverse economic outcomes and adverse economic outcomes of the individual's network. Our study highlights the importance of the association between health and economic well-being as well as potential adverse spill-over effects of poor health on local economies.

Keywords: poor health, regional economic development, longitudinal, economic well-being 


\section{Links between ill health and regional economic performance: Evidence from}

\section{Swedish longitudinal data}

Studies have demonstrated an association between health and economic outcomes both at the national level (see e.g. Lorentzen et al., 2008), and at the individual level (Townsend et al., 1982, Kaplan and Keil, 1993, Adler et al., 1994, Mackenbach et al., 1997, Lynch et al., 2000, Fritzell et al., 2004, Kunst et al., 2005, Subramanian et al., 2002, Subramanian and Kawachi, 2006). While the question of causal direction in the association between health and economic outcomes remains (Deaton, 2002, Marmot, 2002), it is clear that the association is most likely to be reciprocal and that the precise direction of the relationship is likely to be contingent on the precise life stage of the individual. For instance, poor parents will be less able than rich parents to give their children an upbringing that ensures them good health and a competitive education (Smith, 1999), while ill health in adulthood can deprive working adults of income, and thereby reduce their wealth.

In this study, we examine the association between health and economic performance in Sweden, with health defined simply as the absence of sickness. Specifically, we use an extensive longitudinal, individual-level database to explore how ill health affects local economies via the effect on individuals, families and businesses.

The empirical analysis is carried out in three steps, beginning with an analysis of the individuallevel economic effects of sickness. The aim of this analysis was to establish whether a decline in health has severe individual-level economic effects with potential for macro-level repercussions. The second step was to analyze if a severe case of sickness also has economic and social effects on other family members. With this analysis we aim to show that both social and human capital 
explanations are needed to give a full account of the interaction between health events and social or economic outcomes. The third step was to analyze the extent to which a severe case of sickness also has spill-over effects on colleagues employed in the same work place. While there have been earlier studies of the effects of sickness on spouses and children, our study is the first, to the best of our knowledge, to look at the workplace-level spill-over effects of ill health. One reason why ill-health may have a negative effect on economic performance at the regional level is that sickness will lead to a reduction in the individual's productive capacity. But there can also be negative effects beyond the individual level. When for example sickness strikes individuals holding critical positions in organizations and production teams, there may be negative spill-over effects on individuals outside the family.

\section{Data and methods}

We used the PLACE database maintained by the Department of Social and Economic Geography at Uppsala University. This database covers all individuals who have lived in Sweden for some time between 1990 and 2006 (Population, Chorology and Employment Database). It contains yearly, individual-level data from the Swedish population register combined with data on education, residence, employment, employer, family relations and income. The PLACE data does not however have data on occupational status.

The PLACE database measures sickness over time and across different contexts. Although PLACE does not contain any medical information on illness, it provides information on the number of sickness benefits received each year from the Swedish insurance office. Since sickness insurance is mandatory in Sweden, even for the self-employed, this figure can be used to assess the incidence of illness among people who have a job, at least as long as they claim sickness 
benefits. A unique individual identifier code makes it possible to construct 11-year-long histories of employment and income, while a family code makes it possible to link spouses to each other, a parental code allows a linkage of children to parents and a workplace code allows the identification of people who work in the same place.

We focus on spells of sickness and income histories that occurred before and after our midpoint of 1996. This allows us to use pre-1996 data to assess what the situation was like before sickness struck and post-1996 data to assess the situation after sickness struck. We controlled for age by using a single, one-year cohort: individuals born in 1945. Furthermore we excluded from the cohort both individuals who during the 1990 to 1995 period had at least one year without labour income and individuals who during the 1993 to 1995 period received sickness benefits. Excluding individuals with sickness benefits during the pre-1996 period increases the contrast between the period before and after sickness struck and therefore makes it easier to measure the effect of illness. The effect of excluding individuals without labour income in the pre-1996 period is similar. Since poor health is a common cause for not having any labour income, the exclusion of this group makes it possible to remove individuals with health problems before 1996.

The design of our sample ensures that during 1993, 1994 and 1995, no one in the sample received any sickness compensation from the Social Insurance Office. This is also true for the non-sick in 1996, whereas the sick group received an average of SEK 16,000 in sickness compensation in 1996 (the scale is in SEK 100; $1 €$ is approximately SEK 10). The sick group continued to receive substantial sickness compensation after 1996. The continuing reception of sickness compensation after 1996 supports the view that an illness that generates sickness compensation is relatively severe. 
In 1996 a total of 133,754 people belonging to the 1945 cohort were living in Sweden, of which $58.6 \%$ fulfilled the labour income criterion and did not receive any sickness benefits during the 1993-1995 period. This gives us a survey population of 78,408 individuals. Of these, $6.7 \%$, or 5,272 individuals, received sickness benefits in 1996 and are thus classified as belonging to the sick group. The remaining 73,136 did not receive sickness benefits in 1996 and are classified as belonging to the non-sick group. In 1996, sickness benefits were not paid until after 14 days of illness. The reception of sickness benefits therefore indicates that a relatively severe case of illness had occurred.

Having identified sick and non-sick groups we analyzed the development over time of different economic outcome variables and compared the results for sick and non-sick groups both before and after the incidence of illness in 1996. First we examined the averages of different economic outcome variables for the sick and non-sick groups before and after possible sickness struck in 1996. In the data, we were able to follow the development of labour income, capital income, unemployment and sickness benefits as long as the individuals stayed alive and in Sweden [this group consists of 77,080 individuals]. Second, panel regression models were fitted to the data to determine if sickness was associated with different economic outcomes. In this model, year dummies were used to account for changes over time that affect all individuals equally. A group dummy was used to account for differences between the sick and non-sick groups that are constant over time (for example education, ethnic background or life style). A design dummy, finally, captured the effect of sickness. This dummy is 0 for the years 1990-1992, representing the fact that during those years the design allows individuals in the sample to be either sick or non-sick. The design dummy takes the value of 1 in 1993, 1994, and 1995, to reflect the fact that both groups are required to have no sickness benefits during these years. From 1996 to 1999, 
finally, the design dummy was given the value 1 for the healthy group and value -1 for the sick group. The design dummy thus contrasts the effect of staying healthy from 1993-1996 with the effect of staying healthy from 1993-1995 and falling sick in 1996.

The effects of falling sick were measured by comparing economic outcome variables during the 1996-2000 period for the sick group with economic outcome variables from 1993-2000 for the non-sick, and 1993-1995 for the sick group. Regression coefficients and standard errors were used to model this association. The t-statistics given were obtained by dividing the point estimate of the design dummy parameter with the estimated standard error. Spill-over effects were analyzed in a similar way, with the difference being that outcome variables were measured for spouses, children and colleagues of the sick individual. It should be noted that we use observational data and that parameter and error estimates therefore differ from what would be obtained in an experimental study.

\section{Results}

Figures 1 to 3, respectively, show the impact of poor health on a) the individual's economic outcomes, b) the economic outcomes of family members associated with the individual and c) the economic outcomes of workers associated with the individual at the workplace level. In each figure comparisons between the sick and the healthy group are given. 

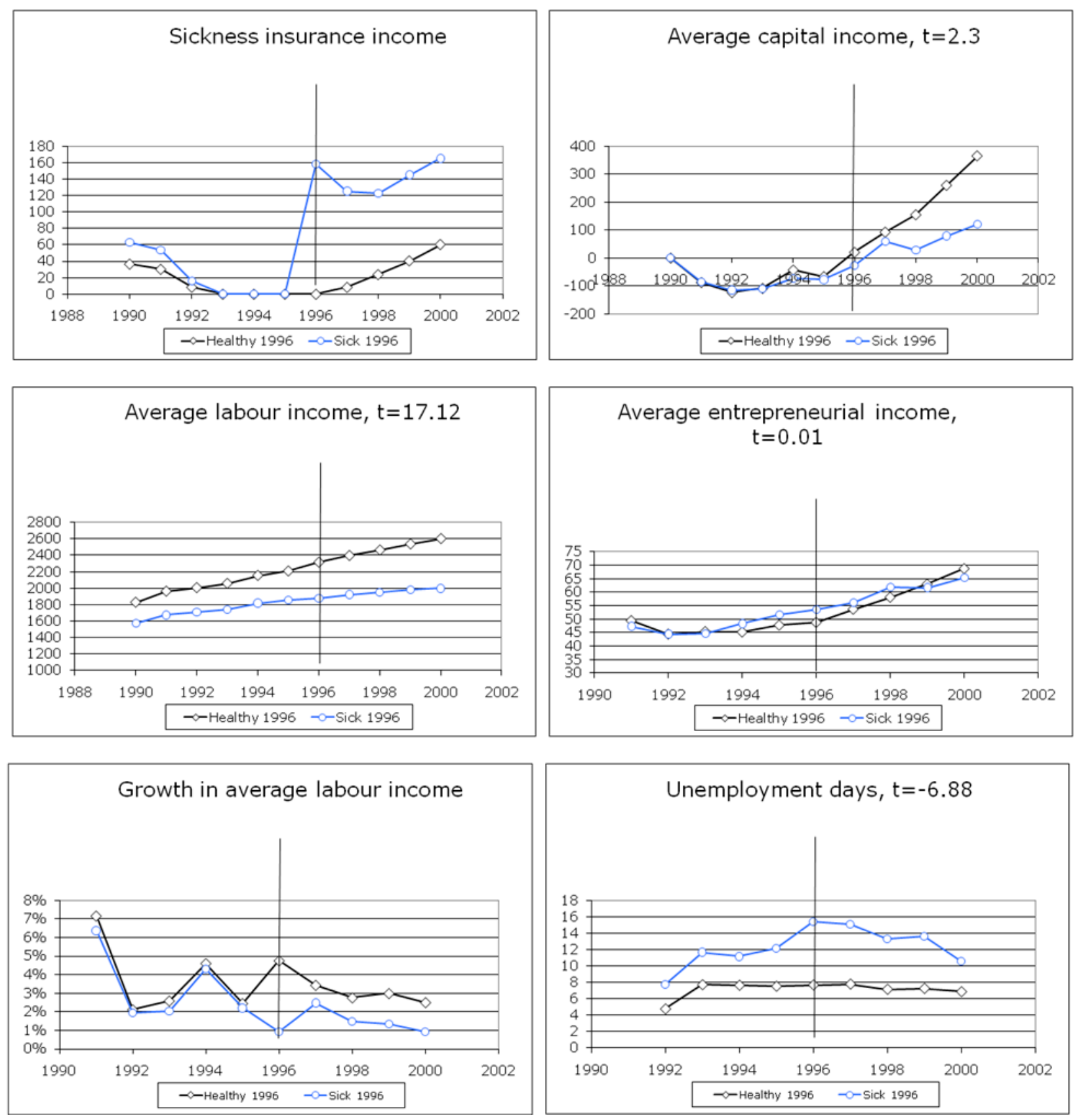

Figure 1. The effect of sickness on sickness insurance income, labour income, growth in labour income, capital income, entrepreneurial income and unemployment days. The t-values are for the effect of sickness during the 19962000 period, controlling for time and group effects. 
Figure 2. The effect of sickness on spouses' sickness payment, labour income, growth in labour income, capital income, unemployment days and welfare benefits. The t-values are for the effect during the 1996-1999 period, controlling for time and group effects.
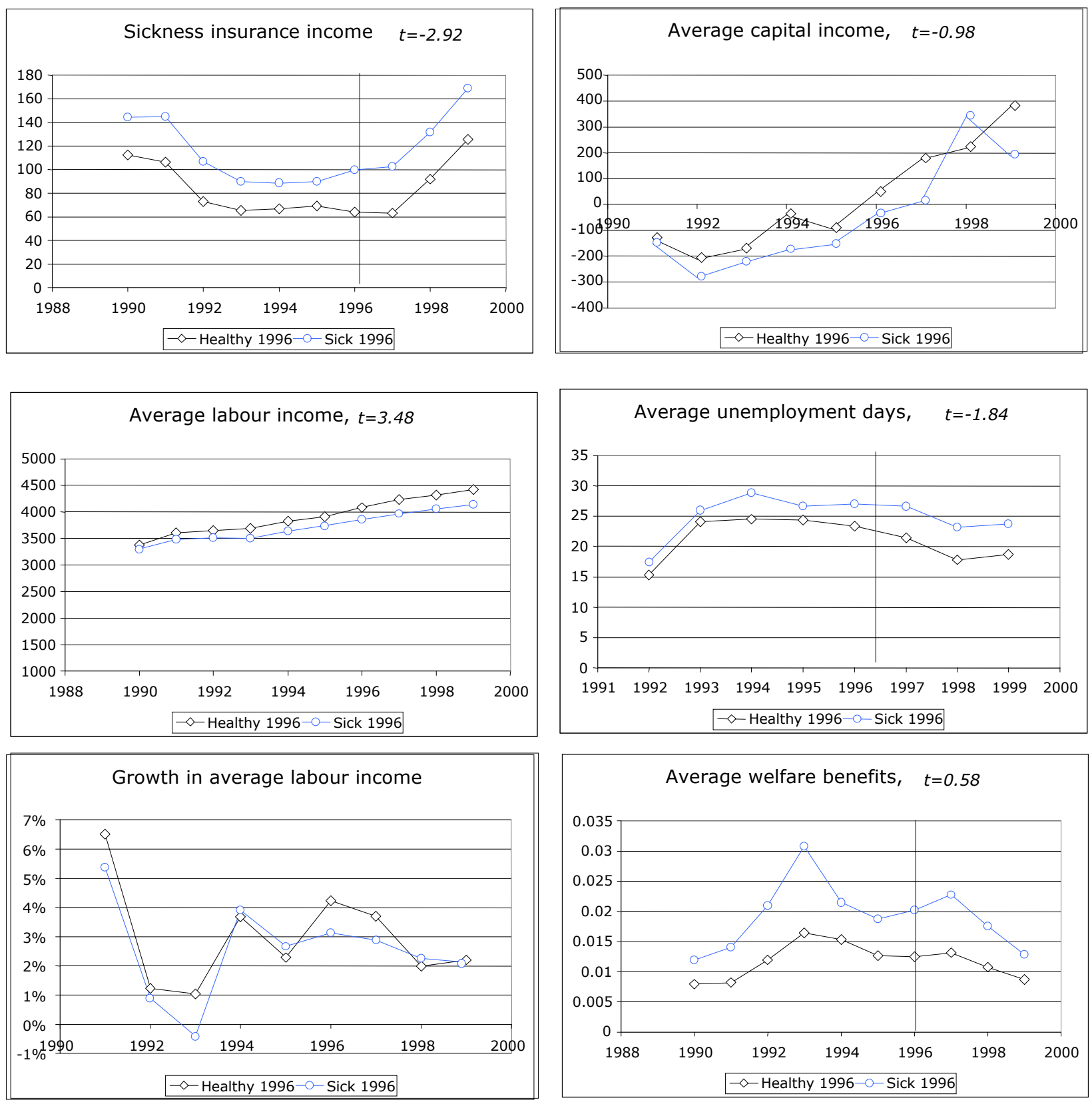

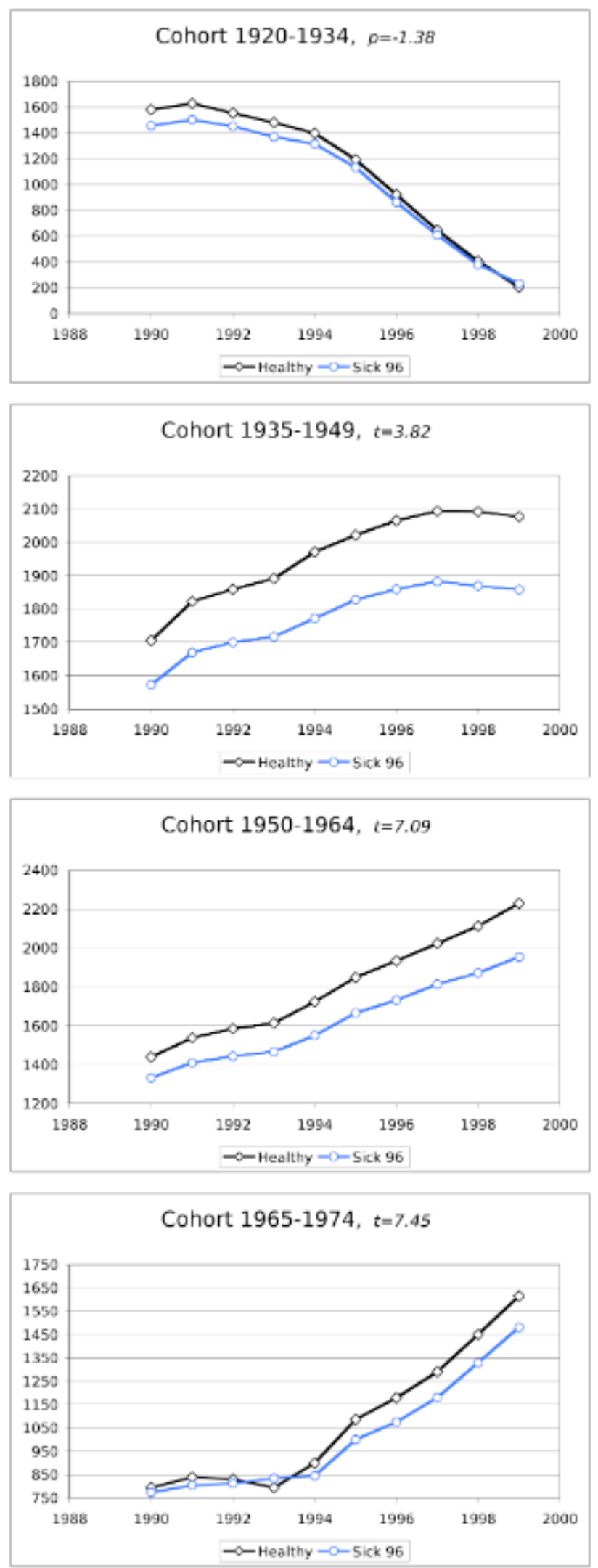

Figure 3. The effect of sickness on the labour income of colleagues, by cohort. The t-values are for the effect during 
the 1996-1999 period, controlling for time and group effects, education and industrial sector.

\section{Impact of poor health on individuals' economic outcomes (Figure 1)}

The sick group already had lower labour income than the non-sick group before sickness struck. This is not surprising given that low income is a risk factor for sickness. It also points to a need for models that reflect the two-way interaction between health and income. It should be noted however that prior to 1996, growth in labour income for the sick group was as fast as for the nonsick group. This suggests that as long as the sick group stayed healthy, they were able to share in the proceeds of rising income. After illness struck this was no longer the case. Then, the sick group experienced a much lower growth in labour income each year compared to the healthy group. The result was a growing gap in labour income from 1996 onwards. The t-statistic of 17.12 confirms that the labour income of the non-sick group was positively affected by the fact that they did not fall sick in 1996.

Since the early 1990s, payments of interest and dividends have been reported directly to the Swedish tax authorities. Data on capital income therefore give a good indication of the financial situation of an individual. Before 1996, both the sick and healthy groups had negative capital income, a result of interest payments on household loans. After 1995, the non-sick group experienced a rapid increase in capital income reflecting a net accumulation of financial assets. The sick group received a positive capital income as well, but their rate of accumulation was much slower. This result is similar to the one reported for the USA by Kim and Lee (2006), using data from the Asset and Health Dynamics Survey.

From a regional perspective this difference is of considerable importance. Various studies have shown that accumulation of capital is an essential pre-condition for successful entrepreneurship 
(see Lindh and Ohlsson, 1998). If individuals struck by sickness have problems accumulating capital this implies a negative effect on the growth of new businesses in regions where the level of ill health is high. Money saved for a rainy day can be invested in new businesses if the weather stays sunny. However if bad luck strikes these savings may have to be used to compensate for lower labour income. Our data do not allow us however to pinpoint any effect of sickness on entrepreneurial income.

Ill-health is also associated, in this data, with a weakened position on the labour market. Even before they became sick, people in the sick group had on average more days of unemployment than the non-sick group. In the year they became sick, this difference increased further. Over time however the number of unemployment days decreased for the sick group, but this may be because they were leaving the labour force altogether. Is higher unemployment in the sick group a cause or an effect of sickness? With our data it is difficult to tell. What this graph does illustrate however is that ill health, whether caused by unemployment or not, can be a factor that makes a return to employment more difficult.

\section{Impact of poor health on the economic outcomes of family members associated with} the individual (Figure 2)

A number of studies have demonstrated that illness in one individual can generate high levels of stress in their spouses, as well as psychiatric disorders like depression. In the case of cancer, for instance, the stress level of the spouse even tends to be higher than the stress experienced by the patient (Northouse et al., 2000). This pattern raises the question of whether we can expect cases of sickness to have negative economic effects on spouses. 
Using the PLACE data, we were able to identify 54,280 spouses of the 78,408 individuals in the survey population. Of these, $6.3 \%$ (3,399 individuals) were related to individuals in the sick group. Our analysis shows that sickness also has negative effects on spouses. As can be generally expected, effects on spouses are not as strong as on the individual falling ill. However, the effects on spouses' sickness and labour income were significant, and marginally significant on unemployment.

Even if the spousal effect is not as strong as the individual effect, it adds force to the argument that poor health can reduce the economic vigour of a region. The picture given here is that an episode of sickness has an effect that goes beyond the immediately affected person (compare Sevak, Weir et al., 2003).

We also analyzed the effect of parental sickness on the labour income of children aged 17 years and above in the year when one of their parents got ill. Children were divided into three five-year age groups: $17-21,22-26$ and 27-31. These age groups reflect different phases with respect to education, labour-market entry and family formation. Here we find a significant negative effect of a parent's ill health on the labour income of older children (aged 27-31 in 1996) but not for children aged 21-26 years old. For younger adolescents (aged 16-21 in 1996) the effect on labour income was positive. The latter effect could be the result of children choosing work instead of education when parental support is reduced. A possible mechanism behind the negative effect on older children's labour income is that reduced parental support forces children to choose jobs that are relatively less demanding in terms of for example length of commutes or extension of working hours. 
The negative economic effects of illness on sick individuals and their spouses, along with spillover effects from parents' sickness to adult children's earnings, indicate that sickness can be seen as one mechanism for the transmission of economic status and health status from parents to children. If sickness strikes, the economic position of the family will be weakened and this in turn may have negative effects on the health and income prospects of children. Conversely, lowincome families that manage to stay healthy will be at least marginally better off compared to low-income families that are affected by illness. This is a possible explanation behind the fact that countries like Sweden, where the social gradient in health is less steep than that in the UK or the United States (van Doorslaer et al., 1997), also have a higher level of social mobility (Solon, 2002).

Impact of poor health on the economic outcomes of workers associated with the individual at the workplace level (Figure 3)

We defined colleagues as individuals who worked in the same workplace as our sample individuals in 1995 , the year before the sick group was struck by illness. The analysis here focused only on the effect on labour income of having a colleague who was affected by a severe illness. Illness should not per se be expected to have an effect on the labour income of colleagues. If there is a perfect substitute who can be hired when a colleague becomes sick the effect should be negligible. However in a workplace that has established a clear division of responsibilities it might be the case that sudden sickness produces some disruption. In the present study we focused on workers who became sick at the age of 51, an age at which many employees have established a relatively strong position at work, one that is often based on a control of resources that are essential for continued efficient operation. Therefore a case of illness in the group under study 
might have a negative effect not only on the individuals themselves and their families, but also on the productivity of the workplace and, by extension, on the labour income of colleagues.

Such negative effects are indeed to be found in the data we analyzed, although not for those who were aged 62 and above at the time their colleague fell ill, where in fact the effect was positive, albeit not significant. It could be that a case of sickness among the most experienced workers forces the employer to ask some 'over-aged' employees to stay on longer. Apart from these older employees however the effect of a 51-year-old colleague falling ill was negative and significant, even more strongly so for employees below 46 years of age.

The individual effect was not very large. The point estimate was SEK 1,900 lower annual income for employees of the 1935-49 cohorts and between SEK 2,700 and 3,000 for cohorts that were younger. What is noteworthy however is that the effect seems to be persistent over time and not limited to the year of illness and the following year. Moreover this is the cost imposed on each employee. Since the mean number of employees is around 22 this implies an annual cost for one case of sickness of about SEK 50,000. This can be compared to the estimated SEK 10,000 effect on the annual labour income of the individual who is struck by sickness. In total it appears that the largest economic effect of a case of illness is on colleagues, taken as a group. Furthermore, if the effect as suggested by the graphs in figure 3 continues for at least four years, the total cost for colleagues would add up to SEK 200,000 for a single case of relatively severe illness. This is not a negligible sum.

An argument against this analysis would be that the effect on the labour income of colleagues in our measure is not the result of having a sick colleague. Instead, both the negative effect on income and the sickness of a colleague could be caused by a third factor, for example layoffs at 
their shared place of work. In fact companies affected by drastic employment reductions between 1994 and 1995 had slightly higher proportions of employees belonging to the sick group.

However eliminating establishments with these negative employment changes did not change the pattern of a negative income effect on colleagues' sickness.

The results presented above indicate that a spell of sickness can have relatively severe economic consequences for the persons directly affected, their spouses (and, by extension, their children) and their colleagues. Lower labour income for people directly and indirectly affected by ill health is a reflection of a lower supply of effective labour. On the aggregate level this implies a less competitive labour force, which means that ill health cannot be ruled out as a negative factor for regional economic development. Clearly there is a need for further studies of how ill health may have spill-over effects on the economic fortunes of related individuals. In this context, qualitative approaches would be a valuable way of gaining a fuller and deeper understanding of the processes.

\section{Comparison with earlier research}

Our finding that sickness has a negative effect on future labour income conforms with the results of earlier studies (see section 3.3.1 in Suhrcke and McKee, 2005). Lower earnings are the result both of a reduction in working hours and of a decline in the level of compensation. Since illness reduces an individual's ability to work, the effect on labour supply is not surprising. On the other hand lower levels of compensation indicate that individuals struck by illness are forced to change jobs or revise their career plans or, possibly, are penalized by their employer because of lower productivity. The negative effects we find on spouses also correspond to the results found in earlier studies (Adams, Hurd et al., 2003, Kennedy, Mcdonald, 2006). 
There have been relatively few studies using European data on the effects of poor health on businesses. Studies from the USA however report negative effects of ill health on workforce productivity. Absenteeism is an important factor here, but also what in this literature is called presenteeism, meaning employees who are unhealthy but still show up at work even though they are not able to work at full capacity. One study estimates that on average, ill health can reduce the effective workforce of a company by as much as $10 \%$ (Berger, Howell et al., 2003). Another study finds that during a two-week period, $13 \%$ of the US labour force lose some productive time due to pain conditions (Stewart, Ricci et al., 2003b, a result that is supported by Pizzi, Carter et al., 2005). Workers with depression report a loss of nearly 6 hours of productive time per week, whereas in the control group, lost productive time was 75\% lower (Stewart, Ricci et al., 2003a; similar results are reported by Adler, Irish et al., 2004; and Marciniak, Lage et al., 2004). A study of special significance with respect to regional considerations was that conducted by Boles, Pelletier et al. (2004), where it was shown that employees with higher health risks report higher levels of impaired performance on the job.

Since high mortality generally only occurs when morbidity is high, our micro-level findings of links between illness and poor economic performance can help to explain why macro-level studies indicate that there is a causal link from health (measured by life expectancy) to economic well-being. For example, studies of cross-country data have demonstrated that life expectancy is one of the best predictors of subsequent economic performance (Knowles and Owen, 1995; Rivera and Currais, 1999; Bhagava, Jamison et al., 2001; Gallup and Sachs, 2001; Mayer, 2001; Mcdonald and Roberts, 2002; Bloom, Canning et al., 2004; Echevarria, 2004; Zhang and Zhang, 2005). Thus, it is not only the case that rising living standards have reduced mortality. Positive 
effects of health on economic performance imply that reductions in mortality have also played a role in triggering economic growth.

Our findings may also be compared with the theoretical literature on why lower mortality contributes to economic growth (Ehrlich and Lui, 1991; De La Croix and Licandro, 1999; Kalemli-Ozcan, Ryder et al., 2000; Blackburn and Cipriani, 2002; Boucekkine, De La Croix et al., 2002; Kalemli-Ozcan, 2002; Bloom, Canning et al., 2003; Kalemli-Ozcan, 2003; Lagerlof, 2003). Two mechanisms have been explored. One is that lower mortality stimulates savings. The extension of life expectancy implies that more people expect to live into old age, and to provide for their consumption during this period of life they increase their level of savings during working life. The saving mechanism is supported by our findings. There is a direct negative effect on the capital income of sickness.

The second mechanism is that increased longevity has a positive effect on the accumulation of human capital. As life expectancy increases investment in education becomes more profitable. This in turn stimulates economic growth. Our business-level findings suggest that there may be a positive human capital effect of improved health, although not one based on formal education but on more efficient on-the-job training.

\section{CONCLUSION}

In this paper we have used a longitudinal database covering the entire Swedish population to track the impact of poor health on individuals, family members, and their business-level coworkers. Our main finding is that poor health not only has a negative impact on earnings, savings 
and the labour market status of individuals struck by illness but that it has spill-over effects on the health and earnings of spouses and the earnings of adult children. Moreover, we find a significant negative impact on the earnings of co-workers.

These findings lend support to the notion that health is not just a product of favourable economic circumstances but also an important determinant of economic well-being. The conclusion is that trajectories of improving or deteriorating health can play a key role in processes of economic development at national, regional and local levels. Health improvements can help lift a region into an upward spiral of positive economic development. Negative health outcomes on the other hand can hurt the productivity of businesses and block economic development.

Thus, instead of ignoring health issues, development policies should be based on an assessment of the health situation in various regions and on an analysis of measures that might help improve the health situation.

\section{REFERENCES}

Adams, P., Hurd, M. D., Mcfadden, D., Merrill, A. \& Ribeiro, T. (2003) “Healthy, wealthy, and wise? Tests for direct causal paths between health and socioeconomic status". Journal of Econometrics, 112, 3-56.

Adler, D. A., J. Irish, et al. (2004). 'The work impact of dysthymia in a primary care population.' General Hospital Psychiatry 26 (4): 269-276. 
Adler, N. E., Boyce, T., Chesney, M. A., Cohen, S., Folkman, S., Kahn, R. L. \& Syme, S. L. (1994) "Socioeconomic status and health--The challenge of the gradient". American Psychologist, 49, 15-24.

Berger, M. L., R. Howell, et al. (2003). 'Investing in healthy human capital.' Journal Of Occupational and Environmental Medicine 45 (12): 1213-1225.

Bhagava, A., D. T. Jamison, et al. (2001). 'Modelling the effects of health on economic growth.' Journal of Health Economics 20 (3): 423-440.

Blackburn, K. and G. P. Cipriani (2002). 'A model of longevity, fertility and growth.' Journal of Economic Dynamics \& Control 26 (2): 187-204.

Bloom, D. E., D. Canning, et al. (2003). 'Longevity and life-cycle savings.' Scandinavian Journal of Economics 105 (3): 319-338.

Bloom, D. E., D. Canning, et al. (2004). 'The effect of health on economic growth: A production function approach.' World Development 32 (1): 1-13.

Boles, M., B. Pelletier, et al. (2004). 'The relationship between health risks and work productivity.' Journal of Occupational and Environmental Medicine 46 (7): 737-745.

Boucekkine, R., D. De La Croix, et al. (2002). 'Vintage human capital, demographic trends, and endogenous growth.' Journal of Economic Theory 104 (2): 340-375.

De La Croix, D. and O. Licandro (1999). 'Life expectancy and endogenous growth.' Economics Letters 65 (2): 255-263. 
Deaton A, (2002). "Policy implications of the gradient of health and wealth" Health Aff (Millwood) 2 13-30

Echevarria, C. A. (2004). 'Life expectancy, schooling time, retirement, and growth.' Economic Inquiry 42 (4): 602-617.

Ehrlich, I. and F. T. Lui (1991). 'Intergenerational Trade, Longevity, and EconomicGrowth.' Journal of Political Economy 99 (5): 1029-1059.

Fritzell, J., Nermo, M. \& Lundberg, O. (2004) "The impact of income: assessing the relationship between income and health in Sweden". Scandinavian Journal of Public Health, 32, 6-16.

Gallup, J. L. and J. D. Sachs (2001). 'The economic burden of malaria.' American Journal of Tropical Medicine and Hygiene 64 (1-2): 85-96.

Kalemli-Ozcan, S. (2002). 'Does the mortality decline promote economic growth?' Journal of Economic Growth 7 (4): 411-439.

Kalemli-Ozcan, S. (2003). 'A stochastic model of mortality, fertility, and human capital investment.' Journal of Development Economics 70 (1): 103-118.

Kalemli-Ozcan, S., H. E. Ryder, et al. (2000). 'Mortality decline, human capital investment, and economic growth.' Journal of Development Economics 62 (1): 1-23.

Kaplan, G. A. \& Keil, J. E. (1993) "Socioeconomic factors and cardiovascular disease-A review of the literature". Circulation, 88, 1973-1998. 
Kennedy, S. \& Mcdonald, J. T. (2006) "Immigrant mental health and unemployment". Economic Record, 82, 445-459.

Kim, H. and J. Lee (2006). "The impact of comorbidity on wealth changes in later life." Journals of Gerontology Series B-Psychological Sciences and Social Sciences 61(6): S307-S314.

Knowles, S. and P. D. Owen (1995). 'Health Capital and Cross-Country Variation in Income Per-Capita in the Mankiw-Romer-Weil Model.' Economics Letters 48 (1): 99106.

Kunst, A. E., Bos, V., Lahelma, E., Bartley, M., Lissau, I., Regidor, E., Mielck, A., Cardano, M., Dalstra, J. A. A., Geurts, J. J. M., Helmert, U., Lennartsson, C., Ramm, J., Spadea, T., Stronegger, W. J. \& Mackenbach, J. P. (2005) “Trends in socioeconomic inequalities in self-assessed health in 10 European countries". International Journal of Epidemiology, 34, 295-305.

Lagerlof, N. P. (2003). 'From Malthus to modern growth: Can epidemics explain the three regimes?' International Economic Review 44 (2): 755-777.

Lindh, T. \& Ohlsson, H. (1998) "Self-Employment and Wealth Inequality". Review-ofIncome-and-Wealth, 44, 25-42.

Lorentzen, P., Mcmillan, J. \& Wacziarg, R. (2008) "Death and development". Journal of Economic Growth, 13, 81-124. 
Lynch, J. W., Smith, G. D., Kaplan, G. A. \& House, J. S. (2000) "Income inequality and mortality: importance to health of individual income, psychosocial environment, or material conditions”. British Medical Journal, 320, 1200-1204.

Mackenbach, J. P., A. E. Kunst, et al. (1997). "Socioeconomic inequalities in morbidity and mortality in western Europe." Lancet 349(9066): 1655-1659.

Marciniak, M., M. J. Lage, et al. (2004). 'Medical and productivity costs of anxiety disorders: Case control study.' Depression And Anxiety 19 (2): 112-120.

Marmot M, (2002). "The influence of income on health: views of an epidemiologist. " Health Aff (Millwood) (2) 31-46

Mayer, D. (2001). 'The long-term impact of health on economic growth in Latin America.' World Development 29 (6): 1025-1033.

Mcdonald, S. and J. Roberts (2002). 'Growth and multiple forms of human capital in an augmented Solow model: a panel data investigation.' Economics Letters 74 (2): 271-276.

Northouse, L. L., Mood, D., Templin, T., Mellon, S. \& George, T. (2000) Couples' patterns of adjustment to colon cancer. Social Science \& Medicine, 50, 271-284.

Pizzi, L. T., C. T. Carter, et al. (2005). 'Work loss, healthcare utilization, and costs among US employees with chronic pain.' Disease Management \& Health Outcomes 13 (3): 201208.

Rivera, B. and L. Currais (1999). "Economic growth and health: direct impact or reverse causation?" Applied Economics Letters 6 (11): 761-764. 
SEVAK, P., WEIR, D. R., and WILLIS, R. J. (2003) The economic consequences of a husband's death: Evidence from the HRS and AHEAD, Social Security Bulletin, 65, pp. $31-44$.

Smith, J. P. (1999). "Healthy bodies and thick wallets: The dual relation between health and economic status." Journal of Economic Perspectives 13(2): 145-166.

Solon, G. (2002) Cross-country differences in intergenerational earnings mobility. Journal of Economic Perspectives, 16, 59-66.

Stewart, W. F., J. A. Ricci, et al. (2003a). 'Lost productive work time costs from health conditions in the United States: Results from the American productivity audit.' Journal Of Occupational and Environmental Medicine 45 (12): 1234-1246.

Stewart, W. F., J. A. Ricci, et al. (2003b). 'Lost productive time and cost due to common pain conditions in the US workforce.' Jama-Journal Of The American Medical Association 290 (18): 2443-2454.

Subramanian S V, Kawachi I, (2006). "Being well and doing well: on the importance of income for health" International Journal of Social Welfare S1: S13-S22

Subramanian S, Belli P, Kawachi I, (2002). "The macroeconomic determinants of health" Annu Rev Public Health 287-302

Suhrcke, M., M. McKee, et al. (2005). The contribution of health to the economy in the European Union. Luxemburg, European Commission, Health \& Consumer Protection Directorate-General. 
Suhrcke, M., M. McKee, et al. (2005). The contribution of health to the economy in the European Union. Luxemburg, European Commission, Health \& Consumer Protection Directorate-General.

Townsend, P., Davidson, N. \& Black, D. (1982) Inequalities in health : the Black report, Harmondsworth, Penguin.

Van Doorslaer, E., Wagstaff, A., Bleichrodt, H., Calonge, S., Gerdtham, U.-G., Gerfin, M., Geurts, J., Gross, L., Häkkinen, U., Leu, R. E., O’Donnell, O., Propper, C., Puffer, F., Rodrìguez, M., Sundberg, G. \& Winkelhake, O. (1997) Income-related inequalities in health: some international comparisons. Journal of Health Economics, 16, 93-112.

Zhang, J. and J. S. Zhang (2005). 'The effect of life expectancy on fertility, saving, schooling and economic growth: Theory and evidence.' Scandinavian Journal of Economics 107 (1): 45-66. 